УДК 94(6):327+94(44):327

ББК 63.3(6)64-6+63.3(4Фра)64-6

\title{
Кто стоит за путчем в Габоне? Исторический контекст
}

\author{
B.P. Филиппов
}

Институт Африки Российской академии наук (Москва, Россия)

\section{Who Is Behind the Attempted Putsch in Gabon? Historical Context}

\author{
V.R. Filippov
}

Institute for African Studies of the Russian Academy of Sciences (Moscow, Russia)

\begin{abstract}
Статья посвящена выяснению причин и последствий неудачной попытки отстранения от власти вооруженным путем президента Габонской Республики Али Бонго Ондимбы. Автор рассматривает ситуацию в Габоне в широком геополитическом контексте и увязывает январские события 2019 г. с политическими процессами в Центральноафриканской Республике и Демократической Республике Конго. Особый акцент сделан на роли Франции, США, России и Китая в борьбе за право участвовать в освоении природных богатств африканских стран и за геостратегическое доминирование в странах субсахарской Африки. Автор рассматривает различные точки зрения на то, кто мог инициировать вооруженный мятеж в Либревиле, но сам при этом склоняется к версии, согласно которой за путчем могут стоять США. В пользу этого предположения говорит то обстоятельство, что А. Бонго на встрече с президентом России Владимиром Путиным в июле 2018 г. высказался за наращивание присутствия России и Китая в африканских странах вообще и в Габонской Республике в частности. Появление американских солдат в Габоне автор объясняет стремлением Вашингтона не допустить расширения военного сотрудничества этой страны с Российской Федерацией, с одной стороны, и намерением дестабилизировать ситуацию в соседней Демократической Республике Конго - с другой.

Ключевые слова: Габонская Республика, Габон, Центральноафриканская Республика, Франция, Демократическая республика Конго, США, Россия, вооруженный мятеж, путч, Али Бонго.
\end{abstract}

DOI 10.14258/izvasu(2019)5-14

Рано утром 7 января 2019 г. пять человек, одетых в форму республиканской гвардии Габона, на армейских джипах блокировали здание государственной радиовещательной станции в Либревиле. Они захва-
The article seeks to clarify the causes and consequences of the unsuccessful attempt to remove from power by force the President of the Gabonese Republic Ali Bongo Ondimba. The author considers the situation in Gabon in a broad geopolitical context and links the events of January 2019 with the political processes in the Central African Republic and the Democratic Republic of the Congo. He emphasizes the role of France, the USA, Russia and China looking for the access to the natural resources of African countries and conquering for the geostrategic dominance in the countries of sub-Saharan Africa. The author considers various points of view on who could initiate an armed insurgency in Libreville, but he himself is inclined to the version according to which the United States can stand behind the coup. This assumption is supported by the fact that, at a meeting with Russian President Vladimir Putin in July 2018, A. Bongo spoke in favor of increasing the presence of Russia and China in African countries in general and in Gabon Republic in particular. The author explains the appearance of American soldiers in Gabon by Washington's desire to prevent the expansion of military cooperation of this country with the Russian Federation, on the one hand, and its intention to destabilize the situation in the neighboring Democratic Republic of the Congo, on the other.

Key words: Gabon Republic, Gabon, Central African Republic, France, Democratic Republic of Congo, USA, Russia, armed insurrection, putsch, Ali Bongo.

тили аппаратную и выступили с обращением к согражданам. Лейтенант Ондо Обианг Келли заявил о конце правления президента Али Бонго Ондимбы, «того, кто трусливо убил юных патриотов в августе 
2016 г.» [1]. (Напомню, тогда в результате столкновений с полицией шесть демонстрантов, протестовавших против фальсификации результатов президентских выборов, получили пулевые ранения и два человека были убиты [2]). Лейтенант провозгласил, что «наступил долгожданный день, когда армия решила встать на сторону народа». Он объявил себя лидером Патриотического движения военных и спецслужб Габона и предложил армии «в интересах нации взять под контроль транспортную систему, запасы боеприпасов и аэропорты» [3]. Лидер путчистов пообещал, что в ближайшие время будет создан Национальный совет восстановления демократии в республике «с целью спасти страну от хаоса» [4], и заявил, что его сподвижники уже контролируют правительство Габона [5]. Позже выяснилось, что это совершенно не соответствовало действительности.

В коммюнике путчистов новогоднее обращение президента страны, который после перенесенного в октябре 2018 г. инсульта не мог двигать правой рукой и с трудом выговаривал некоторые слова, было названо «жалким зрелищем» и «попыткой зацепиться за власть» [3]. Было заявлено, что властная элита продолжает использовать в собственных интересах президента, «лишенного многих физических и умственных способностей» [6]. (А. Бонго был госпитализирован в Саудовской Аравии, а с ноября 2018 г. проходил реабилитацию в Марокко. В новогоднем обращении к нации он заявил, что у него возникли временные трудности со здоровьем, но при этом заверил сограждан, что находится на пути к выздоровлению).

О. Келли эмоционально призвал граждан страны не остаться равнодушными к попытке восстановления демократии и прийти к ним на помощь: «Если ты ешь, остановись. Если ты пьешь, остановись. Если ты спишь, проснись. Разбуди своих соседей. Встаньте как один человек и возьмите под свой контроль улицу» [4]. Из разных источников стало известно, что призыв повстанцев все-таки собрал около трех сотен оппозиционно настроенных граждан, которые попытались прорваться к офису радиовещательной компании [7]. По данным Radio France International (RFI), в Либревиле были слышны выстрелы, а на улицах можно было видеть танки и бронемашины [1]. Бронетранспортеры сил безопасности заблокировали Триумфальный бульвар, главную транспортную магистраль столицы. Известно, что в районе Кокотиерс, расположенном рядом с радиовещательной компанией, десятки молодых людей сожгли автомобиль и подожгли шины. Полиция применила слезоточивый газ для разгона горожан, выступивших в поддержку путчистов.

Через два часа после захвата радиостанции информационное агентство Reuters со слов очевид- цев сообщило, что ситуация в столице в целом остается спокойной [3]. В отдельных районах города были отключены электричество и интернет, а социальные сети были заблокированы [8]. Высокопоставленный армейский чиновник заявил корреспонденту RFI, что лояльные властям силы контролируют все стратегические объекты в стране, а радиостанция окружена. На этом этапе силовики, якобы, не хотели применять силу против мятежников. Однако около 10 часов началась интенсивная перестрелка, полиция и войска, верные правительству, штурмовали захваченную путчистами радиостанцию, в помещении которой, возможно, удерживались заложники.

Вскоре после этого министр по делам коммуникаций Ги-Бертрана Мапонгу, исполняющий обязанности официального представителя правительства, объявил, что «арестованы четверо мятежников, но еще одному удалось бежать». Министр сказал, что «речь идет о группе "шутников", не известных командованию армии Габона», и пообещал, что ситуация в стране полностью нормализуется в течение двух-трех часов [9]. Б. Мапонгу также заверил габонцев, что будет проведено тщательное расследование, что генералы и лидеры оппозиции, упомянутые в заявлении повстанцев в качестве сторонников, будут найдены и арестованы. Позже было объявлено, что четверо путчистов были уничтожены на месте, а скрывшийся солдат «находился в бегах в течение непродолжительного времени», но вскоре «его нашли укрывшимся под кроватью» [3]. Однако ближе к вечеру появилась информация, что только двое путчистов были убиты, а остальные, в том числе лейтенант О. Келли, арестованы [10].

Командующий ВВС Габона Эрик Мбадинга, комментируя эти события, сказал, что попытка переворота стала полной неожиданностью для командования. По его словам, армия всегда считалась верной семье Бонго, так как в ней доминирует президентская гвардия, которая рекрутируется в основном в районе Верхних Огуэ, т.е. в родных местах президентского клана. Все это выглядит тем более странно, что президентская гвардия подчиняется руководству разведки в министерстве обороны, которые соответственно возглавляют брат президента Федерико Бонго и его двоюродный брат Грегуар Куна. Более того, вскоре после подавления путча появилось сообщение о том, что «никто из мятежников в армии Габона никогда не служил» [5].

Понять смысл описываемых событий можно только в широком историческом и геополитическом контексте. После краха французской колониальной империи Габон остался в удушающих объятиях Франции. Вплоть до последнего времени «крошечная, но богатая природными ресурсами страна оставалась псевдогосударством, все еще управляемым 
из Парижа», а «главная роль пластичной габонской политической элиты заключается в содействии освоению французскими компаниями природных и минеральных ресурсов своей страны» [6]. Историки Майкл Рид и Тони Чартер в 1987 г. в статье «Габон: неоколониальный анклав устойчивых французских интересов» писали, что страна «представляет собой крайний случай квазигосударства, граничащий с карикатурой на неоколониальную сущность» [6].

Реакция Елисейского дворца на попытку путча в январе 2019 г. была предсказуемой. Как только стало известно о захвате радиостанции в Либревиле, «французское правительство выступило с осуждением попытки государственного переворота в Республике Габон» [3]. На сайте французского МИДа появилась информация о том, что Франция с большим вниманием следит за событиями, происходящими в Либревиле, и призыв к французским гражданам избегать поездок в Габон. Было заявлено, что Елисейский дворец осуждает любые силовые попытки изменения режима в стране и что «стабильность Габона может быть обеспечена только в строгом соответствии с положениями его Конституции» [11]. Разумеется, этим дело не ограничилось. По тревоге были подняты французские десантники, которые на постоянной основе находятся в Габоне [12]. Мандат этих экспедиционных сил-резидентов заключается в обеспечении политического контроля над государством и защите 8900 французских граждан, которые зарегистрировались в посольстве и работают в Габоне [6]. Как свидетельствует профессор Университета Южной Африки политолог Мартин Рупиа, именно они и сыграли решающую роль в подавлении мятежа. По его словам, «отважные молодые солдаты» были быстро уничтожены «резидентскими французскими и марокканскими экспедиционными силами, насчитывающими около 900 человек, включая этнические батекские войска, тщательно отобранные из родо-племенной общности Бонго» [6].

В контексте нашей темы важно вспомнить следующее. 14 июля 2018 г. А. Бонго посетил Москву, где встретился с Президентом России Владимиром Путиным. Стороны обсудили перспективы сотрудничества и развитие отношений между РФ и Габоном. А. Бонго выразил признательность за то, что РФ в числе первых поздравила его с победой на выборах и в свою очередь поздравил В. Путина с переизбранием. Президент Республики Габон сразу обозначил главный сюжет переговоров с российским коллегой: «Сегодня об Африке все говорят под самыми разными углами зрения. Этот континент обладает богатейшими ресурсами, и сейчас мы наблюдаем, как многие крупные государства борются между собой, чтобы получить доступ к этим богатейшим ресурсам... Господин Президент, я приехал для того, чтобы сказать Вам то, что Вам уже известно: Африка в вас нуждается» [13].

Президент РФ на встрече с А. Бонго заметил, что отношения между Москвой и Либревилем развиваются по всем направлениям и выразил сожаление по поводу того, что объем товарооборота между странами пока сравнительно небольшой. Но особенно важно то, что В. Путин акцентировал внимание на проблемах региональной безопасности в Тропической Африке, подчеркнув, что Габон принимает активное участие и вносит весомый вклад в эту работу. Ответ А. Бонго не мог не вызвать беспокойства в Париже и Вашингтоне. Президент Габона сказал буквально следующее: «Я рад, что Россия неравнодушна к урегулированию конфликта, который находится в непосредственной близости от нас: я имею в виду урегулирование ситуации в Центральноафриканской Республике. У нас есть свой контингент в ЦАР. В настоящее время Габон является председателем Экономического сообщества центральноафриканских государств, и это сообщество непосредственно участвует в урегулировании конфликта в Центральноафриканской Республике. Я думаю, что было бы хорошо, если бы мы объединились и попытались окончательно установить мир в этой стране» [13]. Важно отметить, что по итогам визита А. Бонго в Москву были подписаны несколько крупных соглашений о поставке Габону партии российского оружия [5]. А это значит, что вскоре в Либревиле могут появиться не только нефтяники, но и российские инструкторы, которые будут обучать габонских военных специалистов.

Именно так и случилось в Центральноафриканской Республике в 2018 г. (подробно см.: [14, с. 124-143]). Появление российских военных (пусть в форме без знаков различия), которые обеспечивают безопасность не только президента ЦАР Ф.-А. Туадеры, но и российского бизнеса в этой стране, вызывает серьезную озабоченность на Западе. Пожелавший остаться неназванным чиновник из структур $\mathrm{OOH}$ констатировал: «Все они (страны Запада. - В.Ф.) встревожены, они не знают, что делать. Они не ожидали прихода русских!» [15]. Некий дипломат европейской страны, работающий в ЦАР, апокалиптически оценивает перспективы присутствия стран EC на Черном континенте: «Россия делает дело, а мы говорим. Такое складывается впечатление. И это верное впечатление... Если мы отдадим ЦАР, мы отдадим всю Африку» [15]. Размышляя о путях возвращения России в Африку, французская журналистка А. Реневьер заметила: «Кремлю потребовалось около 20 лет, чтобы постепенно вернуться на континент. На этот раз не с идеологией, а с контрактами» [16]. Однако думать, что сейчас Москва в отношениях с африканскими странами руководствуется сугубо прагматичными соображениями, 
было бы явным упрощением. Известный французский политолог А. Дюбьен справедливо отмечает, что «сегодня Россия пытается превратить старые узы идеологической дружбы (там, где они еще существуют) в геоэкономическое влияние» [17]. Именно этим состоянием умов объясняется участие французских военных в оперативном подавлении военного мятежа в Габонской Республике и появление американских солдат в этой стране непосредственно накануне этого события.

За два дня до неудавшегося путча в Либревиле Дональд Трамп направил 80 американских военных в Габонскую Республику под предлогом защиты граждан США и американских дипломатических объектов в Демократической Республике Конго (ДРК) [3]. Американцы прибыли в Габон при поддержке авиации и с соответствующим боевым снаряжением. Было заявлено, что Белый дом стремится избежать повторения ситуации в Бенгази, где в 2012 г. из-за отсутствия возможности срочной переброски сил быстрого реагирования террористы убили американского посла. Д. Трамп со свойственной ему детской непосредственностью объявил, что американские солдаты будут находиться в регионе «пока не станет ясно, что их присутствие больше не нужно», и что в зависимости от ситуации численность этого контингента может быть увеличена (цит. по: [1]).

Дело в том, что 30 декабря 2018 г. в ДРК прошли выборы президента, в результате которых власть в этой многострадальной стране впервые в истории сменилась демократическим путем. Правительство настаивало на том, что выборы были честными и прошли без значительных эксцессов. Впрочем, наблюдатели и лидеры оппозиции объявили, что выборы были омрачены серьезными нарушениями. В связи с этим международное сообщество выразило обеспокоенность сложившейся ситуацией: многие эксперты полагали, что оспариваемый результат может спровоцировать массовые беспорядки, как это уже случалось после президентских выборов в 2006 и 2011 гг.

Результаты выборов Национальная независимая избирательная комиссия опубликовала утром 10 января 2019 г., победителем был объявлен кандидат от оппозиции Феликс Антуан Чисекеди Чиломбо [18]. Через несколько дней, 19 января, Верховный суд страны подтвердил его полномочия. Таким образом, Антуан Чисекеди стал первым оппозиционным кандидатом, выигравшим президентские выборы в ДРК с 1960 г., т. е. с момента, когда страна впервые обрела независимость [19].

Результаты этих выборов, очевидно, не устроили западных ревнителей демократии. Госдепартамент США призвал Избирательную комиссию обеспечить точный подсчет голосов и пригрозил наложить санкции против тех, кто подорвал демократический процесс и поставил под угрозу мир и стабильность в стране. Дипломатические ведомства Франции, Бельгии, Великобритании также поставили под сомнение победу А. Чисекеди. Министр иностранных дел Пятой Республики неожиданно заявил, что «результаты президентских выборов... не соответствуют ожиданиям» и что «Мартин Файулу должен был априори стать победителем» [20]. (Отметим, что один из кандидатов на пост президента М. Файулу был в недалеком прошлом топ-менеджером крупнейшей американской нефтяной компании Exxon Mobil). Представитель конголезского правительства Ламбер Менде в ответ на этот выпад главы французского дипломатического ведомства сказал, что он «решительно не одобряет тот факт, что иностранный сановник позволяет себе подобные высказывания», что он «расценивает их как типичный случай вмешательства во внутренние дела его страны» (цит. по: [21]). Понятно, кого и почему «коллективный Запад» хотел бы видеть во главе ДРК, и почему победа А. Чисекеди не устроила страны НАТО: велика была угроза потерять контроль над этой бедной страной, чрезвычайно богатой самыми разнообразными природными ресурсами. Здесь есть золото, алмазы, серебро, кобальт, молибден, но, главное, здесь сосредоточены 80\% мировых запасов колтана, который абсолютно необходим для производства мобильных телефонов.

Уместно также вспомнить, что ДРК продемонстрировала свою заинтересованность в военном сотрудничестве с Россией: в мае 2017 г. наша страна восстановила конвенцию, предусматривающую российское военное присутствие в этом африканском государстве, а также обучение конголезских военных в России.

Удивление вызывает тот факт, что американские солдаты отправлены защищать граждан США в Габон, а не в ДРК, где им, якобы, угрожает опасность, а также то, что американцы появились в Габонской республике непосредственно перед попыткой государственного переворота в Либревиле. Обращает на себя внимание и то обстоятельство, что Габон не имеет общей границы с ДРК: территории этих государств разделяет территория суверенной Республики Конго. Американского президента все это ничуть не смущает, но у независимых наблюдателей порождает сомнения относительно истинных целей этой военной экспедиции. А таковых может быть две. Во-первых, воспрепятствовать появлению российских военных специалистов в Габоне, если вдруг А. Бонго захочет обратиться за помощью к Москве в случае опасного для него развития событий. (Такой сценарий вполне возможен: вспомним недавнее появление российской ЧВК «Вагнер» в Центральноафриканской республике.) Во-вторых, 
дестабилизировать обстановку в ДРК, если странам НАТО не удастся политическими средствами добиться дискредитации А. Чисекеди и пересмотра результатов президентских выборов в ДРК.

Полезно вспомнить, что в конце 2018 г. советник президента США Джон Болтон упрекнул Россию и Китай в наращивании «финансового и политического влияния по всей Африке» и направлении инвестиций в страны Черного континента «с целью получить преимущество перед США» [22].

Неправильно было бы рассматривать ситуацию в Габоне вне общего политического ландшафта Африки южнее Сахары. Многие обозреватели, которые пишут о проникновении России в Африку, отмечают, что «Москва сделала себя необходимой в таких странах, как Судан, Ангола, Мозамбик и Нигерия. Тесные отношения существуют у нее также с Эфиопией и Зимбабве» [23]. Все чаще говорят о «дуге российского влияния», которая протянулась из Судана в Анголу, от Хартума до Луанды через Банги и Киншасу [24]. Недружественные по отношению к России СМИ констатируют: «Влияние
России в Африке растет от Судана до Анголы. Наследники Советского Союза не ограничиваются политическим вмешательством, занимаясь одновременно беспринципным бизнесом» [25].

Сейчас пока трудно сказать, кто стоит за попыткой отстранения А. Бонго от власти, кто непосредственно инициировал вооруженный мятеж. Системная оппозиция сразу же после ареста и устранения мятежников объявила о своей полной непричастности к попытке захвата власти вооруженным путем. Некоторые эксперты склоняются к мысли о том, что путч организовали молодые романтики, которые сознательно пошли на смерть во имя демократии и прогресса в их стране. Другие говорят о попытке западных спецслужб «лишить Россию потенциального африканского союзника» [7]. Сразу после описанных событий была озвучена точка зрения, согласно которой «за путчем могут стоять США, поскольку габонский лидер выступает за активизацию присутствия в Африке России и Китая» [22]. Последняя версия представляется мне наиболее вероятной.

\section{Библиографический список}

1. Калюков Е. Военные в Габоне объявили о захвате власти для восстановления демократии. URL: https://www. rbc.ru/politics/07/01/2019/5c330b4a9a794770e85c72a1.

2. Gabon Election 2016: Clashes as Bongo Beats Jean Ping. URL: https://www.aljazeera.com/news/2016/08/gabon-electionprotests-ali-bongo-beats-jean-ping-160831183011584.html.

3. Gabon Coup Attempt: Government Says Situation under Control. URL: https://www.bbc.com/news/worldafrica-46779854.

4. Jaulmes A. Putsch manqué au Gabon. URL: http:// www.lefigaro.fr/international/2019/01/07/0100320190107ARTFIG00249-putsch-manque-au-gabon.php.

5. Гостев А. «Проснитесь и занимайте улицы»: как провалился военный переворот в Габоне. URL: https:// ru.krymr.com/a/kak-provalilsya-voenniy-perevorot-vgabone/29697258.html.

6. Rupiya M.R. Three Reasons Why the Gabon Coup Failed. URL: https://mg.co.za/article/2019-01-09-threereasons-why-the-gabon-coup-failed.

7. Россия едва не лишилась африканского союзника. URL: https://news.rambler.ru/africa/41533368-rossiya-edvane-lishilas-afrikanskogo-soyuznika/.

8. Армия Габона заявила, что не поддерживает захвативших радиостанцию военных. URL: https://ria. $\mathrm{ru} / 20190107 / 1549084819 . \mathrm{html}$.

9. В столице Габона арестовали мятежных военных. URL: https://ria.ru/20190107/1549085127.html.
10. Gabon: des militaires arrêtés après avoir appelé à un soulèvement URL: http://www.lefigaro.fr/ international/2019/01/07/01003-20190107ARTFIG00048gabon-a-la-radio-d-etat-des-militaires-appellent-a-unsoulevement.php.

11. France Diplomatie. Gabon (7 janvier 2019). URL: https://www.diplomatie.gouv.fr/fr/dossiers-pays/gabon/ evenements/article/gabon-07-01-19.

12. Кусов В.Г. Правители Африки: XXI век. URL: https:// africanrulers.ru/main/biographies/gabon_bongo_a/.

13. Meeting with President of Gabon Ali Bongo Ondimba. URL: http://en.kremlin.ru/events/president/news/57996.

14. Филиппов В.Р. Центральноафриканская республика: противостояние Кремля и Елисейского дворца // Локус. 2019. № 1.

15. Vinograd C. There's a New Battle for Influence in Central Africa, and Russia Appears to Be Winning. URL: https://www.washingtonpost.com/news/worldviews/wp/ 2018/05/31/theres-a-new-battle-for-influence-in-centralafrica-and-russia-appears-to-be-winning/?noredirect $=$ on\&utm_term $=.97 \mathrm{a} 50 \mathrm{c} 7 \mathrm{c} 1590$.

16. Renevier A. Le grand retour de la Russie en Afrique. URL: https://information.tv5monde.com/afrique/le-grandretour-de-la-russie-en-afrique-222424.

17. Dubien A. La Russie s'intéresse également à la nouvelle Afrique. URL: http://afrique.lepoint.fr/economie/arnauddubien-la-russie-s-interesse-egalement-a-la-nouvelleafrique-page-2-25-10-2017-2167405_2258.php. 
18. Félix Tshisekedi remporte la présidentielle en RDC URL: https://www.lecho.be/economie-politique/ international/afrique/felix-tshisekedi-remporte-lapresidentielle-en-rdc/10085840.html.

19. DR Congo Presidential Election: Church Questions Results. URL: https://www.bbc.com/news/world-africa-46827760.

20. Présidentielle en RDC: la France met en doute les résultats URL: http://www.rfi.fr/afrique/20190110presidentielle-rdc-france-met-doute-resultats.

21. Belsoeur C. Le regard gênant d'ingérence de Jean-Yves Le Drian sur la présidentielle en RDC. URL: https://www. slate.fr/story/172146/le-drian-republique-democratiquecongo-election-presidentielle-regard-ingerence?amp.
22. Камран Г. Кто стоит за попыткой военного переворота в Габоне. URL: https://tsargrad.tv/articles/kto-stoit-zapopytkoj-voennogo-perevorota-v-gabone_177476.

23. Signer D. Wie Russland afrikanische Krisenländer infiltriert. URL: https://www.nzz.ch/international/wierussland-afrikanische-krisenlaender-infiltriert-ld.1389297.

24. Dietrich T. En Centrafrique, un parfum de guerre froide. URL: https://www.lopinion.fr/edition/international/ en-centrafrique-parfum-guerre-froide- 156731.

25. Нелюбин Е. Президент ЦАР доверил свою безопасность россиянам. URL: https://www.bfm.ru/news/391294. 